\title{
Bimanual simultaneous motor performance and impaired ability to shift attention in Parkinson's disease
}

\author{
M W I M Horstink, H J C Berger, K P M van Spaendonck, J H L van den Bercken, \\ A R Cools
}

\begin{abstract}
The ability to share time and to shift attention between bimanual simultaneous motor tasks were studied in 18 patients with Parkinson's disease (PD) and 19 age- and intelligence-matched controls. The task consisted of drawing triangles with the dominant hand and squeezing a rubber bulb with the nondominant hand. Motor performance was measured using the variables: amplitude of squeezing, frequency of squeezing and velocity of drawing triangles. After eliminating variance due to baseline differences in single-handed performance, the bimanual simultaneous performance of $P D$ and controls turned out to be similar to the frequency of squeezing and the velocity of drawing triangles. The amplitude of squeezing, however, differed between the two groups: it was significantly reduced in PD. Arguably the disturbance in the bimanual performance of PD patients was not due to a disorder of time sharing, but to a decreased ability to shift attention from the visually cued task to the non visually cued task. The results agree with current evidence that $P D$ patients are more impaired when they have to rely upon internal control for the regulation of shifting attention than when external cues are available.
\end{abstract}

Temporal and spatial processing is involved in the simultaneous performance of two separate single-handed tasks. The timing of bimanual simultaneous tasks is a function of one generalised time-programme, ${ }^{1-5}$ a phenomenon also referred to as time-sharing. ${ }^{4}$ The spatial performance of both tasks is executed by two separate concurrently running motorprogrammes that are controlled by shifting attention from one task to the other. ${ }^{46}$

Patients with Parkinson's disease (PD) are known to have much more difficulty than controls when simultaneously performing two separate single-handed tasks, even though they can perform each of these tasks separately ${ }^{6-10}$ Their performance turns out to be task dependent: separate single movements are executed simultaneously in $\mathrm{PD},{ }^{610}$ but repetitive movements sequentially. ${ }^{9} \quad$ PD patients are apparently disabled when simultaneous repetitive movements are involved. Correct performance of such repetitive simultaneous tasks depends on the capability of sharing time and shifting attention. To our knowledge, time-sharing during repetitive simultaneous movements has not been studied in PD. As far as the ability to shift attention is concerned, several authors reported that PD patients have problems with shifting set; ${ }^{71-19}$ set being defined as a process of focussed and sustained attention predisposing a subject to respond in one way when several alternatives are available. ${ }^{1718}$ Such shifting deficiency is associated with hypofunctioning of the dopaminergic system. ${ }^{20}$

In this study, a simplified test of Schwab et $a l^{9}$ was used to evaluate both time sharing and shifting attention. The dominant hand drew triangles, while the non-dominant hand at the same time repeatedly squeezed a rubber bulb. Drawing fixed triangles is strongly determined by external cues, while squeezing of a rubber bulb almost entirely depends on internal control. We therefore expected that squeezing in PD patients would be more impaired than drawing triangles, since PD patients are impaired when they have to rely upon internal control for regulating attention, but are relatively unimpaired when external cues or guidance are given. ${ }^{161921}$

\section{Subjects}

Eighteen patients with idiopathic PD (without thalamotomy) and nineteen controls were studied. All patients regularly attended the outpatient department of movement disorders and gave their informed consent. The patients had been clinically stable for at least one month before the examination. Relevant data and disease factors are summarised in table 1.

PD patients and controls were well matched for age, intelligence and attention. Five subtests of the WAIS were used to assess intelligence (score (SD)): Vocabulary (PD: 36.12 (9.74); controls: 41.05 (9.02)), Similarities (PD: $16 \cdot 33$ (5.34); controls: $17 \cdot 47$ (4.17)), Picture Completion (PD: 10.50 (3.09); controls: 11.37 (3.51)), Block Design (PD: 10.67 (4.43); controls: $12 \cdot 16(5 \cdot 19))$ and Digit Span (PD: 11.78 (2.73); controls: 12.32 $(3 \cdot 84))$. Deficits in attention were assessed with the Stroop Colour Word Test by subtracting the duration of Stroop Colour Word Test-2 from that of the Stroop Test- $3^{22} 23$ (PD: 58.83 (20.70); controls: $49.32(17.00))$. The differences between the group means were not significant (MANOVA, SPSSX: $F=0.85$, df $=6$ and $30 ; p>0.05)$. Depression was excluded by clinical examination and enquiries among family members. 
Table 1 Demographic data and disease factors in Parkinson's disease (PD)

\begin{tabular}{|c|c|c|c|c|c|c|c|c|c|c|c|}
\hline \multirow[b]{2}{*}{$\begin{array}{l}\text { Pat } \\
n r\end{array}$} & \multirow[b]{2}{*}{$\begin{array}{l}\text { Age } \\
\text { yrs }\end{array}$} & \multirow[b]{2}{*}{$\begin{array}{l}P D \\
y r s\end{array}$} & \multicolumn{2}{|c|}{ Levodopa } & \multicolumn{2}{|c|}{ Antichol } & \multicolumn{2}{|c|}{ Webster } & \multicolumn{2}{|c|}{ Hypokin } & \multirow[b]{2}{*}{$\begin{array}{l}H-Y \\
\text { stage }\end{array}$} \\
\hline & & & $y r s$ & $m g / d$ & $y r s$ & $m g / d$ & $\begin{array}{l}R \\
\text { arm }\end{array}$ & $\begin{array}{l}L \\
\text { arm }\end{array}$ & $\begin{array}{l}R \\
\text { arm }\end{array}$ & $\begin{array}{l}L \\
\text { arm }\end{array}$ & \\
\hline $\begin{array}{r}1 \\
2 \\
3 \\
4 \\
5 \\
6 \\
7 \\
8 \\
9 \\
10 \\
11 \\
12 \\
13 \\
14 \\
15 \\
16 \\
17 \\
18\end{array}$ & $\begin{array}{l}63 \\
66 \\
70 \\
69 \\
67 \\
71 \\
47 \\
50 \\
51 \\
59 \\
41 \\
47 \\
58 \\
70 \\
63 \\
67 \\
68 \\
64\end{array}$ & $\begin{array}{r}5.5 \\
3.0 \\
4.0 \\
1.5 \\
4.5 \\
6.0 \\
5.0 \\
6.5 \\
5.0 \\
1.5 \\
5.5 \\
6.5 \\
7.5 \\
14.5 \\
5.0 \\
4.0 \\
11.5 \\
7.0\end{array}$ & $\begin{array}{l}0.25 \\
- \\
0.25 \\
\overline{1.5} \\
\overline{2} \\
2.0 \\
- \\
\overline{-} \\
5.5 \\
5.0 \\
6.0 \\
3.0 \\
3.0 \\
6.0 \\
5.0\end{array}$ & $\begin{array}{l}400^{1} \\
{ }^{2} \\
{ }^{4} 400^{1} \\
400^{1} \\
{ }^{*} 300^{1} \\
\star \\
\star \\
-4600^{2} \\
400^{1} \\
3200^{2} \\
200^{1} \\
200^{1} \\
3500^{2} \\
600^{1}\end{array}$ & $\begin{array}{l}4.5 \\
2.5 \\
- \\
2.5 \\
\overline{2} .5 \\
2.5 \\
2.5 \\
1.5 \\
- \\
6.5 \\
13.0 \\
3.5 \\
9.0 \\
6.0\end{array}$ & $\begin{array}{l}150^{1^{4}} \\
- \\
\overline{150^{3}} \\
\overline{150^{3}} \\
150^{3} \\
150^{3} \\
200^{3} \\
- \\
\overline{150^{3}} \\
300^{3} \\
- \\
1^{4} \\
4^{5} \\
150^{3}\end{array}$ & $\begin{array}{l}2 \\
4 \\
3 \\
6 \\
2 \\
4 \\
1 \\
2 \\
6 \\
5 \\
3 \\
3 \\
7 \\
5 \\
5 \\
2 \\
5 \\
2\end{array}$ & $\begin{array}{l}5 \\
4 \\
2 \\
2 \\
3 \\
3 \\
1 \\
2 \\
2 \\
5 \\
4 \\
4 \\
3 \\
4 \\
7 \\
7 \\
7 \\
2\end{array}$ & $\begin{array}{l}1 \\
2 \\
1 \\
2 \\
1 \\
1 \\
1 \\
1 \\
2 \\
2 \\
1 \\
2 \\
3 \\
2 \\
2 \\
1 \\
2 \\
1\end{array}$ & $\begin{array}{l}2 \\
2 \\
1 \\
1 \\
1 \\
1 \\
1 \\
1 \\
1 \\
2 \\
1 \\
2 \\
1 \\
2 \\
2 \\
2 \\
2 \\
1\end{array}$ & $\begin{array}{l}3 \\
3 \\
1 \\
2 \\
3 \\
2 \\
1 \\
2 \\
2 \\
2 \\
2 \\
3 \\
3 \\
3 \\
3 \\
2 \\
4 \\
1\end{array}$ \\
\hline $\begin{array}{l}\text { mean } \\
\text { SD }\end{array}$ & $\begin{array}{r}60 \cdot 8 \\
9 \cdot 3\end{array}$ & $\begin{array}{l}5.8 \\
3.1\end{array}$ & $\begin{array}{l}3 \cdot 3 \\
2 \cdot 3\end{array}$ & & & & $\begin{array}{l}3.7 \\
1.6\end{array}$ & $\begin{array}{l}3.7 \\
1.8\end{array}$ & $\begin{array}{l}1.5 \\
0.6\end{array}$ & $\begin{array}{l}1.4 \\
0.5\end{array}$ & $\begin{array}{l}2.3 \\
0.8\end{array}$ \\
\hline
\end{tabular}

Abbreviations: Webster: sum of tremor, hypokinesia and rigidity scores of upper extremity according to Webster rating scale. Abbreviations: Webster: sum of tremor, hypokinesia and rigidity scores of upper extremity according to Webster Hypokin: Webster hypokinesia score of the upper extremity. R: right side, L: left side. H-Y: Hoehn-Yahr scale. $\mathrm{mg} / \mathrm{d}$ : $\mathrm{mg} / \mathrm{day}$;

${ }^{1}$ : Levodopa plus decarboxylase inhibitor; ${ }^{2}$ : levodopa; ${ }^{3}$ : orphenadrine- $\mathrm{HCl}^{4}{ }^{4}$ : dexetimide; ${ }^{5}:$ benzatropine; ${ }^{\star}$ : amantadine $200 \mathrm{mg}$.

\section{Methods}

Single-handed performance was assessed by means of two tasks: squeezing with the nondominant hand (Sq) and drawing triangles with the dominant hand (Tr). Bimanual simultaneous performance was assessed by two tests: simultaneously squeezing and drawing triangles $(\mathrm{Sq}+\mathrm{Tr})$ and simultaneously squeezing and writing the letter e $(\mathrm{Sq}+\mathrm{ee})$. The single-handed and the bimanual tests lasted $15 \mathrm{~s}$ each.

The tests were administered in the following constant order: 1 Squeezing with nondominant hand $(\mathrm{Sq})$ : subjects were instructed to squeeze the bulb repeatedly and as quickly as possible by fully opening and closing the hand. This task served as the baseline squeezing performance.

2 Drawing triangles with dominant hand (Tr): subjects were instructed to connect without interruption, and as quickly as possible, the fixed angle points of a triangle with 9 $\mathrm{cm}$ sides. This task served as the baseline triangle performance.

$3 \mathrm{Sq}$ and $\mathrm{Tr}$ simultaneously $(\mathrm{Sq}+\mathrm{Tr})$ : subjects squeezed $(\mathrm{Sq})$ with the non-dominant hand while the dominant hand simultaneously drew triangles ( $\mathrm{Tr}$ ).

$4 \mathrm{Sq}$ and ee simultaneously ( $\mathrm{Sq}+\mathrm{ee})$ : to ensure that a decrease in performance was not due to the complexity of the tasks, subjects also performed a simpler test (Bloxham et $\left.a l^{4}\right)$. In this test the dominant hand wrote a series of lower case e's while the non-dominant hand was squeezing.

All ergograms were recorded with an electrowriter which transformed the two-dimensional movements of the dominant hand into the one-dimensional movements of the recording pen. The recorded distance was proportional to the actual performance. Only a minimal effort was required for squeezing the bulb. Subjects were seated in a quiet room with only the experimenter present. The experimenter first demonstrated the standard procedure, after which the subjects practised each test twice, each trial lasting about 10 s. This appeared to be sufficient for familiarising them with the technical equipment. There was a 60 s break between the performances. Characteristic performance by controls and PD patients are shown in figs $1 \mathrm{~A}, \mathrm{~B}$.

\section{Design and data analysis}

The following three variables were studied: 1 ) Amplitude of $\mathrm{Sq}$, that is, mean excursion of the recording pen in $\mathrm{cm}$. 2) Frequency of $\mathrm{Sq}$, that is, number of squeezes per $5 \mathrm{~s} .3$ ) Velocity of drawing triangles, that is, trajectory of the recording pen in $\mathrm{cm} / 5 \mathrm{~s}$. The recordings did not allow for accurate measurements of the velocity of writing the lower case e's. Performance during each test was analysed from the first recorded movement and not from the moment at which subjects were instructed to start.

The data were collected according to a design, in which we focussed on differences between PD patients and controls for bimanual simultaneous motor performance. By contrasting bimanual with single-handed performance confounding baseline differences in single-handed performance were eliminated. In our paradigm there was one betweensubjects factor with two levels: controls and PD. Motor performance was a within-subjects factor also with two levels: single-handed performance and bimanual simultaneous performance. The analysis of variance of the resulting repeated measures design was based on a multivariate approach in which bimanual performance was compared with single-handed performance by means of difference scores. ${ }^{25}$ Since motor performance was measured by a number of variables, there were several difference scores for the contrast of single- 

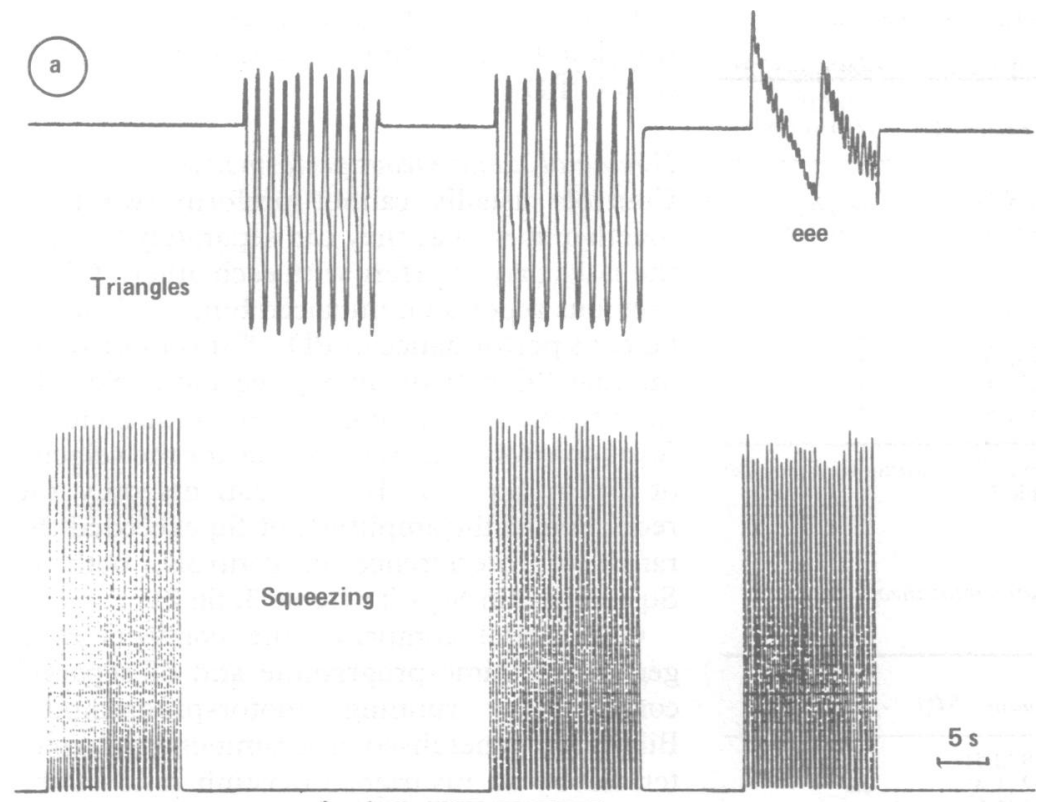

Figure $1 \mathrm{~A}$ Single-handed and bimamul simultaneous performance in a control. From left to right: single-handed squeezing (lower trace), single-handed drawing of triangles upper trace), squeezing and simultaneous drawing of triangles, and squeezing and simultaneous writing of the letter ' $e$ '.
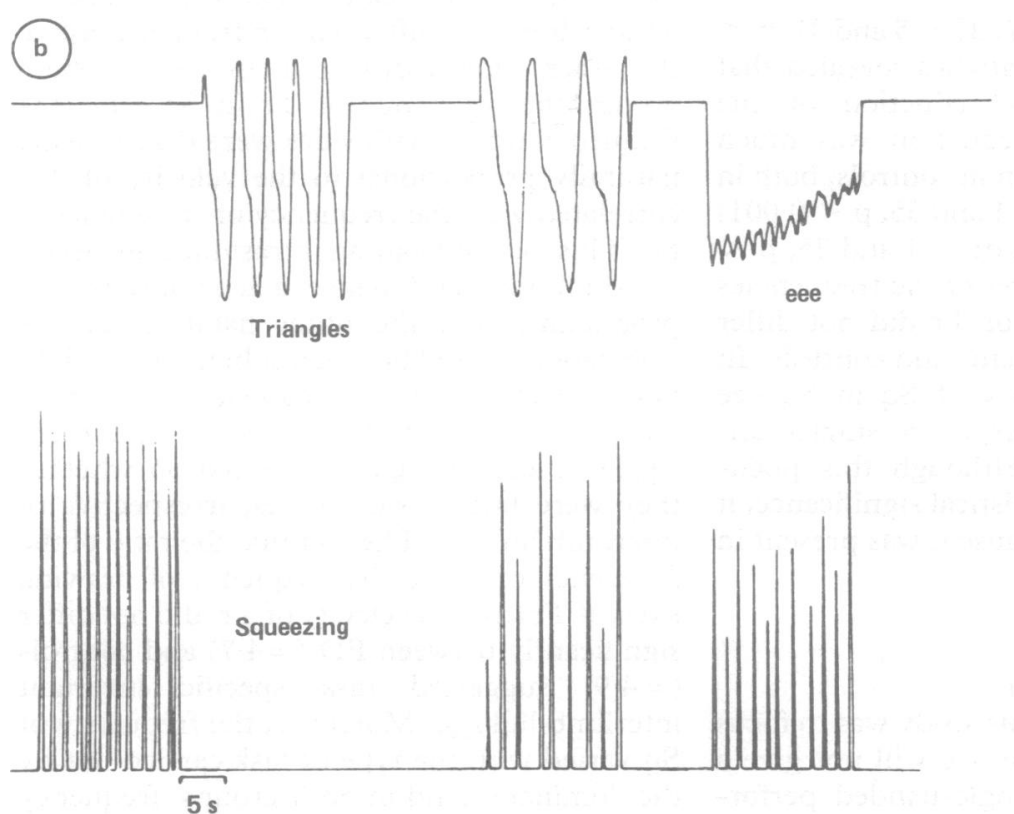

Figure $1 B$ Single-handed and bimanual simultaneous performance in Parkinson's disease. Legends see fig $1 \mathrm{~A}$.

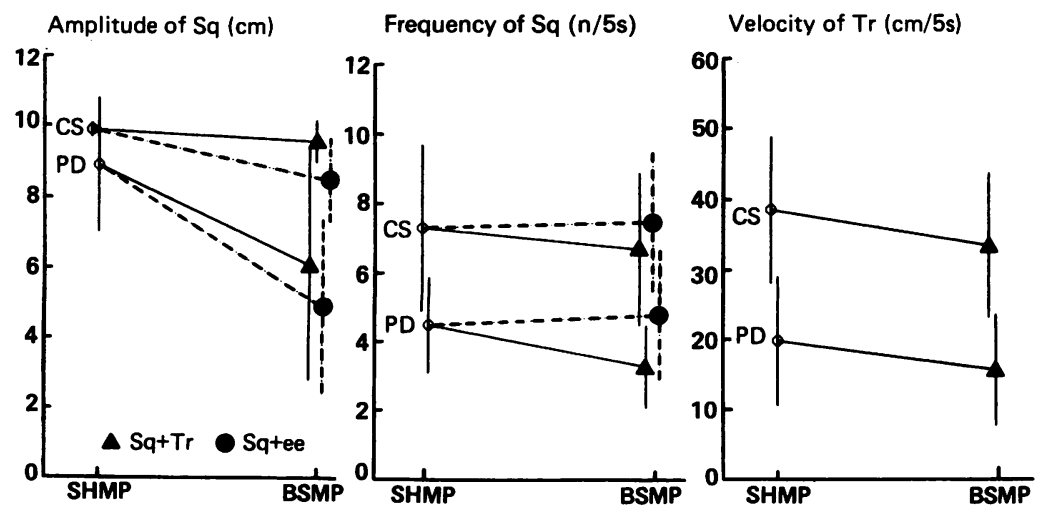

Figure 2 Mean and $S D$ of amplitude of squeezing $(S q)$, frequency of $S q$ and velocity of drawing triangles ( $T r$ ) during single-handed (SHMP) and bimanual simultaneous motor performance (BSMP) in patients with Parkinson's disease (PD) and controls (CS). handed and bimanual performance. Both multivariate and univariate statistics are reported. Pearson correlation coefficients were used to assess the correlations between the variables of motor performance. The analysis was performed by the SPSSX procedure MANOVA. ${ }^{26}$

\section{Results}

Correlations between amplitude of $S q$, frequency of $S q$ and velocity of $\mathrm{Tr}$.

Performance $S q$ was measured with two variables: amplitude and frequency. During singlehanded Sq these variables were not significantly correlated in PD $(r=0.13, p>0.05)$. In controls the amplitude of $\mathrm{Sq}$ was inversely proportional to the frequency of $\mathrm{Sq}(r=$ $-0.46, p<0.05)$. In the Sq+ee and $\mathrm{Sq}+\mathrm{Tr}$ tests, there was no correlation between amplitude and frequency of $\mathrm{Sq}$ in either $\mathrm{PD}$ $(\mathrm{Sq}+$ ee: $\mathbf{r}=0.37, \mathrm{p}>0.05 ; \mathrm{Sq}+\mathrm{Tr} ; \mathrm{r}=$ $-0.25, \mathrm{p}>0.05)$ or controls $(\mathrm{Sq}+\mathrm{ee:} \mathbf{r}=$ $-0.25, \mathrm{p}>0.05 ; \mathrm{Sq}+\mathrm{Tr}: \mathrm{r}=-0.38, \mathrm{p}>$ $0.05)$. In both groups the amplitudes of $\mathrm{Sq}$ in $\mathrm{Sq}+$ ee and $\mathrm{Sq}+\mathrm{Tr}$ were correlated (PD: $\mathbf{r}=$ $0.79, \mathrm{p}<0.001$; controls: $\mathrm{r}=0.59, \mathrm{p}<0.01$ ). The same held true for the frequencies of $\mathrm{Sq}$ in Sq + ee and Sq + Tr (PD: $r=0.49, p<0.05$; controls: $r=0.85, p<0.001)$. In $\mathrm{Sq}+\mathrm{Tr}$ velocity of $\mathrm{Tr}$ correlated with frequency of $\mathrm{Sq}$ in both PD ( $\mathrm{r}=0.43, \mathrm{p}<0.05)$ and controls $(\mathrm{r}$ $=0.73, \mathrm{p}<0.001)$. There was no correlation between the amplitude of Sq and the velocity of $\mathrm{Tr}$ in either group. (PD: $\mathrm{r}=0 \cdot 16, \mathrm{p}>0.05$; controls: $r=-0.22, p>0.05)$.

\section{Single-handed performance}

The results of single-handed performance in PD and controls are shown in table 2. Both groups differed significantly as shown by a multivariate test (Wilks' Lambda $=0.31, F=$ 11 , df $=3$ and 33, $p<0.001)$. During singlehanded $\mathrm{Sq}$ the amplitude of $\mathrm{Sq}$ in $\mathrm{PD}$ equalled $90 \%$ of the amplitude of $\mathrm{Sq}$ in controls $(\mathrm{F}=$ $4.90, \mathrm{df}=1$ and $35, \mathrm{p}<0.05)$. The difference in frequency of Sq was greater: frequency of Sq in $\mathrm{PD}$ equalled $62 \%$ of the frequency found in controls $(F=17.27, \mathrm{df}=1$ and $35, \mathrm{p}<0.001)$. Finally, the difference in the velocity of drawing $\operatorname{Tr}$ was most striking: velocity in PD only equalled $51 \%$ of that displayed by the controls $(\mathrm{F}=20.80, \mathrm{df}=1$ and $35, \mathrm{p}<0.001)$.

Bimanual simultaneous performance of $P D$ patients versus controls

Bimanual simultaneous performance of PD patients was compared with that of controls (table 2, fig 2).

Our main interest was in differences in bimanual motor performance over and above differences in baseline performance. This was achieved by using difference scores between variables of single-handed and bimanual performance as dependent variables in the analysis of variance (see design and data analysis). The data are shown in table 3. PD patients and controls appeared to differ significantly for the set of difference scores as a whole (Wilks' 
Table 2 Motor performance of $P D$ patients and controls in single-handed and bimanual simultaneous tasks

\begin{tabular}{|c|c|c|c|c|}
\hline Task & Variable & $C S$ mean $(S D)$ & $P D$ mean $(S D)$ & $\begin{array}{l}P \text { of } F \\
P D \text { vs } C S\end{array}$ \\
\hline $\begin{array}{l}\text { Single-hande } \\
\text { Sq } \\
\text { Sq } \\
\text { Tr }\end{array}$ & $\begin{array}{l}\text { ampl } S q(\mathrm{~cm} / 5 \mathrm{~s}) \\
\text { freq } \mathrm{Sq}(\mathrm{n} / 5 \mathrm{~s}) \\
\text { vel } \operatorname{Tr}(\mathrm{cm} / 5 \mathrm{~s})\end{array}$ & $\begin{array}{c}9 \cdot 9(0 \cdot 2) \\
7 \cdot 3(2 \cdot 4) \\
38 \cdot 5(10 \cdot 4)\end{array}$ & $\begin{array}{r}8.9(1.9) \\
4.5(1.4) \\
19.8(9.3)\end{array}$ & $\begin{array}{l}<0.05 \\
<0.001 \\
<0.001\end{array}$ \\
\hline $\begin{array}{c}\text { Bimanual sim } \\
\text { Sq }+\mathrm{Tr} \\
\text { Sq }+\mathrm{Tr} \\
\text { } \mathbf{q}+\mathrm{Tr} \\
\mathrm{Sq}+\mathrm{ee} \\
\mathrm{Sq}+\mathrm{ee}\end{array}$ & $\begin{array}{l}\text { ampl } \mathrm{Sq}(\mathrm{cm} / 5 \mathrm{~s}) \\
\text { freq } \mathrm{Sq}(\mathrm{n} / 5 \mathrm{~s}) \\
\text { vel } T r(\mathrm{~cm} / 5 \mathrm{~s}) \\
\text { ampl } \mathrm{Sq}(\mathrm{cm} / 5 \mathrm{~s}) \\
\text { freq } \mathrm{Sq}(\mathrm{n} / 5 \mathrm{~s})\end{array}$ & $\begin{array}{c}9.6(0.6) \\
6.7(2.2) \\
33.4(10.3) \\
8.5(1.2) \\
7.5(2.0)\end{array}$ & $\begin{array}{r}6.1(3.3) \\
3.3(1.2) \\
15.6(8.0) \\
4.9(2.5) \\
4.8(1.9)\end{array}$ & $\begin{array}{l}\star \\
\star \\
\star \\
\star \\
\star\end{array}$ \\
\hline
\end{tabular}

Abbreviations: PD: Parkinson's disease; CS: controls; Sq: squeezing; Tr: drawing triangles; ee: writing e's; ampl: amplitude; freq: frequency; vel: velocity. ^See table 3.

Table 3 Difference scores between single-handed and bimanual simultaneous performance of $P D$ patients versus controls

\begin{tabular}{|c|c|c|c|c|}
\hline Task & Variable & $C S$ mean $(S D)$ & $P D$ mean $(S D)$ & $\begin{array}{l}P \text { of } F \\
P D \text { vs } C S\end{array}$ \\
\hline $\begin{array}{l}\text { Sq vs } S q+T r \\
S q \text { vs } S q+T r \\
S q \text { vs } S q+T r \\
S q \text { vs } S q+e e \\
\text { Sq vs } S q+e e\end{array}$ & $\begin{array}{l}\text { ampl Sq }(\mathrm{cm} / 5 \mathrm{~s}) \\
\text { freq } S q(\mathrm{n} / 5 \mathrm{~s}) \\
\text { vel } \operatorname{Tr}(\mathrm{cm} / 5 \mathrm{~s}) \\
\text { ampl } S q(\mathrm{~cm} / 5 \mathrm{~s}) \\
\text { freq } S q(\mathrm{n} / 5 \mathrm{~s})\end{array}$ & $\begin{array}{r}-0.3(0.6) \\
-0.6(1.3) \\
-5.1(9.9) \\
-1.4(1.2) \\
0.2(1.7)\end{array}$ & $\begin{array}{r}-2 \cdot 8(2 \cdot 5) \\
-1 \cdot 2(1 \cdot 4) \\
-4 \cdot 2(7 \cdot 3) \\
-4 \cdot 0(2 \cdot 1) \\
0.3(1 \cdot 8)\end{array}$ & $\begin{array}{l}<0.05 \\
\text { ns } \\
\text { ns } \\
<0.001 \\
\text { ns }\end{array}$ \\
\hline
\end{tabular}

Legends: see table 2. opinion, the latter differences also reflected well-known difficulties in executing a motor plan in PD. ${ }^{29-33}$

\section{Bimanual simultaneous performance}

Controls usually cannot perform two tasks together as well as they can separately because the tasks may interfere with each other. ${ }^{4}$ Given previous reports on impaired bimanual simultaneous performance in $P D,{ }^{6-10}$ it is most striking that PD patients in $\mathrm{Sq}+$ ee and in $\mathrm{Sq}+\mathrm{Tr}$ showed the same changes in the frequencies of $\mathrm{Sq}$ as controls. The same is true for the velocity of $\mathrm{Tr}$ in $\mathrm{Sq}+\mathrm{Tr}$. In PD patients only the reduction in the amplitude of Sq exceeded the range of interference in controls, both in $\mathrm{Sq}+$ ee and in $\mathrm{Sq}+\operatorname{Tr}$ (table 3, fig 2).

Our model comprises the concepts of a generalised time-programme and of separate concurrently running motor-programmes. Bilaterally generalised programmes are characterised by an invariant interlimb ratio of the pertinent variable. ${ }^{634}$ On the contrary, if a variable has a variant interlimb ratio, then the pertinent aspect of movement is supposedly executed by separate concurrent programmes. ${ }^{634}$ In the latter case, performance depends on the ability to shift attention from one task to the other while carrying them out. ${ }^{4}$ In both groups the frequency of $\mathrm{Tr}$ in $\mathrm{Sq}+\mathrm{Tr}$ (the frequency which with sides were drawn being naturally proportional to the velocity of $\mathrm{Tr}$ ) correlated with the frequency of simultaneous Sq. This may indicate an intrasubject invariant interlimb ratio and, hence, a generalised timeprogramme. On the other hand, since the correlation existed between subjects this might have reflected that the frequency with which individuals simultaneously performed squeezes and triangles depended on whether they were fast or slow types, irrespective of interlimb linkage. The fact that the ratio of the frequency of $\mathrm{Sq}$ to the frequency of drawing sides of $\operatorname{Tr}$ (that is, velocity of $\mathrm{Tr}$ ) did not differ significantly between PD $(=4 \cdot 7)$ and controls $(=4.9)$ suggested task specific invariant interlimb linkage. Moreover, the frequency of Sq varied with the type of task carried out by the dominant hand in both groups: frequency of $\mathrm{Sq}$ tended to increase in $\mathrm{Sq}+\mathrm{ee}$ and decreased in Sq $+\mathrm{Tr}$. Apparently, in both PD and controls the type of task of the dominant hand determined the pace of Sq. These results not only suggest that both groups adapted the timing of the one hand to the other, but also that both groups adapted it in the same way, indicating that PD patients constructed a generalised time-programme as controls supposedly do. ${ }^{1-5}$

Such a bilaterally generalised timeprogramme in $\mathrm{Sq}+\mathrm{Tr}$ indicates that $\mathrm{Sq}$ and $\mathrm{Tr}$ were executed simultaneously in PD. In fact, most of our patients drew continuously: their ergograms of ee and $\mathrm{Tr}$ showed hardly any gaps. Gaps would be obvious if the bimanual tasks were executed sequentially in $\mathrm{Sq}+\mathrm{ee}$ and $\mathrm{Sq}+\mathrm{Tr}$. This observation is contrary to those of Schwab et al that PD patients do not perform repetitive movements simultaneously, but sequentially. However, it must be noted 
that our drawing test was less difficult than the one used by Schwab et al; the instruction to draw perpendicular lines in the triangle being omitted. Their observations probably hold true for more complex tasks.

During bimanual simultaneous performance, the frequency and the amplitude of Sq did not correlate in either group. This indicates that these variables represented independent processes. The observation that in controls both variables were negatively correlated during single-handed $\mathrm{Sq}$ only indicates that time constraints did induce mutual dependency. ${ }^{5}$ These results agree with our frame of reference that both variables corresponded to distinct processes in the brain, that is, frequency corresponded to time-sharing and amplitude to spatial performance.

In $\mathrm{Sq}+\mathrm{Tr}$ the amplitude of $\mathrm{Sq}$ did not correlate with the spatial performance of $\mathrm{Tr}$ : although all subjects did in fact draw $T r$ accurately according to the fixed scheme, amplitudes of Sq varied clearly (table 2, fig 2). This variant interlimb ratio agrees with the conclusions of $\mathrm{Keele}^{5}$ and Poulton ${ }^{4}$ that the spatial performances of separate bimanual simultaneous tasks are not executed by one generalised motor programme, but by two concurrent motor programmes. Correct performance of such concurrent motor programmes relies on the ability to shift attention between both tasks. ${ }^{46}$ Because in both $\mathrm{Sq}+\mathrm{ee}$ and in $\mathrm{Sq}+\mathrm{Tr}$ the reduction in the amplitude of Sq was significantly greater in PD than in controls, we conclude that the PD patients had a diminished capacity to shift their attention to Sq.

The question remains as to why there was no significant difference between PD and controls in the reduction of velocity of $\mathrm{Tr}$ during $\mathrm{Sq}+\mathrm{Tr}$, compared with single-handed $\mathrm{Tr}$ (table 3, fig 2). PD patients apparently concentrated on $\mathrm{Tr}$ and did not shift attention to Sq, presumably because visual cues or guidance, as present in $\mathrm{Tr}$, take priority over non-visual, that is, sensory ones, as present in Sq. ${ }^{45}$ Such a procedure yields further evidence that $\mathrm{PD}$ patients depend on external cues or guidance to shift from one movement to another. ${ }^{1623313236}$ They fail to shift attention when they have to rely upon internal control ${ }^{161920}$ as was the case in Sq in Sq + Tr: Sq lacked imperative external cues or guidance to prompt attention and to divert it from $\mathrm{Tr}$.

In our paradigm all subjects had to squeeze a rubber bulb. Squeezing did not require much effort, and so we looked upon the amplitude of $\mathrm{Sq}$ as a variable of spatial performance, this variable representing the trajectory of hand and finger movements. Nevertheless, due to the construction of the technical equipment, the rubber bulb also transduced some force. Hence, theoretically, the amplitude of Sq comprised some characteristics of the variable force, which would imply that the patients had difficulty controlling the force they put into their movement, because they could not pay attention to it. However, we certainly did not measure isometric squeezing. As far as we could judge from our own experience and from that of the patients and controls, the greater part of squeezing resulted from isotonic muscle contraction. But, what is more important, the main purpose of this study was to evaluate the ability to shift attention between two simultaneous motor tasks. The question of whether the amplitude of $\mathrm{Sq}$ represented spatial performance or force did not influence our conclusions in that respect: in both cases an impairment of shifting of attention will produce a lower amplitude of Sq.

The deficit in bimanual simultaneous performance in $\mathrm{Sq}+\mathrm{Tr}$ did not correspond to the complexity of the task: the amplitude of $\mathrm{Sq}$ in $\mathrm{Sq}+$ ee was also affected (fig 2) despite the fact that PD patients performed ee more easily than $\operatorname{Tr}$ (Bloxham et $a l^{24}$ ). Nor could simple fatigue ${ }^{27}$ account for this impairment. If fatigue played a prominent role in the performance of the bimanual tasks, the velocity of $\mathrm{Tr}$ would also be affected. Certainly, the velocity of $\mathrm{Tr}$ was reduced in $\mathrm{Sq}+\mathrm{Tr}$ in $\mathrm{PD}$ patients, but only to the same degree as seen in controls (table 3, fig 2).

We conclude that in PD the disturbance of bimanual simultaneous performance of the present tasks was not due to a decreased ability to share time between the two tasks. The deficit in bimanual simultaneous performance was, however, apparently caused by the fact that PD patients were unable to shift their attention sufficiently from one of the simultaneous tasks to the other. These experiments yield further evidence that PD patients are more impaired in the regulation of their attention when they have to rely upon internal control than when external visual cues or guidance are available.

1 Peters M. Simultaneous performance of two motor activities: the factor of timing. Neuropsychol 1977;15: $461-4$

2 Kelso JAS, Southard DL, Goodman D. On the coordination of two-handed movements. J Exp Psychol 1979;5:229-38.

3 Klapp ST. Doing two things at once: the role of temporal compatibility. Memory and Cognition 1979;7:375-81.

4 Poulton EC. Human Manual Control. In: Brookhart JM, Mountcastle VB, Geiger SR, eds. Handbook of Physiology, Mountcastle VB, Geiger SR, eds. Handbook of Physiology,
section I The Nervous System vol II, part 2. Bethesda: section I The Nervous System vol II, part 2.

5 Keele SW. Behavioral analysis of movement. In: Brookhart JM, Mountcastle VB, Geiger SR, eds. Handbook of JM, Mountcastle VB, Geiger SR, eds. Handbook of
Physiology, section I The Nervous System vol II, part 2 . Bethesda: American Physiological Society 1981, 1391-414.

6 Benecke R, Rothwell JC, Dick JPR, Day BL, Marsden CD. Performance of simultaneous movements in patients with Parkinson's disease. Brain 1986;109:739-57.

Talland GA, Schwab RS. Performance with multiple sets in Parkinson's disease. Neuropsychol 1964;2:45-53.

8 Horne DJ de L. Sensorimotor control in parkinsonism. $J$ Neurol Neurosurg Psychiatry 1973;36:742-6.

9 Schwab RS, Chafetz ME, Walker S. Control of two simultaneous voluntary motor acts in normals and in parkinsonism. Arch Neurol Psychiatry 1954;72:591-8.

10 Stelmach GE, Worringham CI The control of bimanual aiming movements in Parkinson's disease. J Neurol aiming movements in Parkinson's

11 Buchwald NA, Hull CD, Levine MS, Villablanca J. The Basal Ganglia and the regulation of response and cognitive sets. In: Brazier MAB, ed. Growth and development of the brain. New York: Raven Press 1975:171-89.

12 Bowen FP. Behavioral alterations in patients with basal ganglia lesions. In: Yahr MD, ed. The Basal Ganglia. (Res Publ Ass Res Nerv Ment Dis, vol 55). New York: Raven Press 1976:169-77.

13 Lees AJ, Smith E. Cognitive deficits in the early stages of Parkinson's Disease. Brain 1983;106:257-70.

14 Hietanen $M$, Teravainen $H$. Cognitive performance in early Parkinson's disease. Act Neurol Scand 1986;73:151-9.

15 Taylor AE, Saint-Cyr JA, Lang AE. Frontal lobe dysfunction in Parkinson's disease. Brain 1986;109:845-84.

16 Cools AR, Bercken JHL van den, Horstink MWIM, Spaen donck KPM van, Berger HJC. Cognitive and moto 
shifting aptitude disorder in Parkinson's disease. $J$ Neurol Neurosurg Psychiatry 1984;47:443-53.

17 Flowers KA, Robertson C. The effect of Parkinson's disease on the ability to maintain a mental set. J Neurol Neurosurg Psychiatry 1985;48:517-29.

18 Brown RG, Marsden CD. Neuropsychology and cognitive function in Parkinson's diseae. In: Marsden CD, Fahn S, function in Parkinson's diseae. In: Marsden CD, Fahn S,
eds. Movement Disorders 2. London: Butterworth Scieneds. Movement Disor

19 Brown RG, Marsden CD. An investigation of the phenomenon of "set" in Parkinson's disease. Movement Dis 1988;3:152-61.

20 Berger HJC, van Hoof JJM, van Spaendonck KPM, Horstink MWIM, van den Bercken JHL, Jaspers R, Cools AR. Haloperidol and cognitive shifting. Neuropsychol 1989;27:629-39.

21 Brown RG, Marsden CD. Internal versus external cues and the control of attention in Parkinson's Disease. Brain 1988;111:323-46.

22 Jensen AR, Rowler WD. The Stroop Color word test: a review. Act Psychol 1966;25:36-93.

23 van Spaendonck KPM, Berger HJC, Horstink MWIM, Jaspers RMA, Cools AR. Cognitive performance in early Jaspers RMA, Cools AR. Cognitive performance in

24 Bloxham CA, Mindel TA, Frith CD. Initiation and execution of predictable and unpredictable movements in Parkinson's disease. Brain 1984;107:371-84

25 Hand DJ, Taylor CC: Multivariate analysis of variance and repeated measures. London: Chapman and Hall, 1987.

26 SPSSX User's Guide, 2nd ed. New York: McGraw Hill Book Company, 1986.
27 Schwab RS, England AC, Peterson E. Akinesia in Parkinson's disease. Neurol 1959;9:65-72.

28 Fahn S. Fluctuations of disability in Parkinson's disease. In: Marsden CD, Fahn S, eds. Movement Disorders. London: Butterworth Scientific 1982:123-45.

29 Benecke R, Rothwell JC, Dick JPR, Day BL, Marsden CD. Disturbance of sequential movements in patients with Parkinson's disease. Brain 1987;110:361-80.

30 Wing AM, Miller E. Basal Ganglia lesions and psychological analysis of the control of voluntary movement. In: Evered analysis of the control of voluntary movement. In: Evered D, O'Connor M, eds. Function

31 Flowers KA. Visual "closed loop" and "open loop" characteristics of voluntary movement in patients with Parkinsonism and intention tremor. Brain 1976;99:269-310.

32 Flowers $\mathrm{K}$. Lack of prediction in the motor behaviour of Parkinsonism. Brain 1978;101:35-52.

33 Georgopoulos AP, DeLong MR, Crutcher MD. Relations between parameters of step-tracking movements and single cell discharge in the globus pallidus and subthalamic nucleus of the behaving monkey I Neurosci 1983;3:1586-98.

34 Carter MC, Shapiro DC. Control of sequential movements: evidence for generalized motor programs. J Neurophysiol 1984;52:787-96.

35 Peters M. Attentional asymmetries during concurrent bimanual performance. Ouart J Exp Psychol 1981;33a: bimanual 103 .

36 Stern Y. Patients with Parkinson's disease can employ a predictive motor strategy. J Neurol Neurosurg Psychiatry 1986;49:107-8. 